\title{
SISTEM INFORMASI SEKOLAH MADRASAH ALIYAH NEGERI 1 SAMARINDA BERBASIS WEB
}

\author{
Shinta Palupi ${ }^{1)}$, Yulindawati ${ }^{2)}$, Rina Mardiana ${ }^{3)}$ \\ ${ }^{1,3}$ Sistem Informasi, Stmik Widya Cipta Dharma \\ ${ }^{2}$ Teknik Informatika, Stmik Widya Cipta Dharma \\ $1,2,3$ Jl. Prof. M. Yamin No. 25, Samarinda, 75123 \\ E-mail : caca_200177@gmail.com ${ }^{1)}$,yuli.linda08@yahoo.com ${ }^{2)}$, rinagugi@gmail.com ${ }^{3)}$
}

\begin{abstract}
ABSTRAK
Penelitian ini dibuat untuk mengatasi berbagai kendala yang dihadapi oleh Madrasah Aliyah Negeri 1 Samarinda , dalam membangun website ini didukung sistem database MySQL dan menggunakan Dreamweaver sebagai web editor yang didukung Apache sebagai web server, serta bantuan dari alat bantu pengembangan system flowchart serta menggunakan bahasa PHP ( PHP Hypertext Preprocessor ) yang memiliki fasilitas diantaranya halaman utama, galery ,sejarah dan informasi lainnya yang berkaitan dengan sekolah .
\end{abstract}

Metode yang digunakan dalam pengembangan web ini adalah waterfall sedangkan metode pengujian yang dipakai adalah blackbox dan beta.

Dengan dibangunnya website ini maka akan diperoleh manfaat yang besar bagi sekolah, juga memberikan kemudahan dalam menerima dan memberi informasi-informasi yang dibutuhkan oleh setiap Siswa, guru dan Seluruh Masyarakat pada umumnya.

Kata kunci : Informasi, Sekolah, Madrasah Aliyah,Website, Waterfall, Blackbox, Beta.

\section{PENDAHULUAN}

Dunia internet semakin lama berkembang karena manusia selalu mencari terobosan baru. Dalam perkembangan sebuah sistem informasi jarak jauh yang memberikan hak akses khusus bagi anggotanya sudah banyak yang menggunakanya. Dengan perkembangan teknologi yang semakin pesat, sarana dan prasarana pendidikan harus mengikutinya, salah satunya dengan media komputerisasi yaitu internet. Dengan internet dimana siswa maupun guru dapat mengakses ilmu pengetahuan dan informasi kapan saja dan dimana saja.

Banyak sekali manfaat dari internet . salah satunya pembuatan sistem informasi berbasis web, Informasi merupakan salah satu kebutuhan masyarakat yang sangat penting diera globalisasi seperti sekarang ini. Kini masyarakat semakin mudah mendapatkan informasi yang diinginkan melalui berbagai macam media dan salah satunya adalah media internet, yang merupakan hasil kemajuan dari teknologi yang terus berkembang. Teknologi website dalam perkembangannya telah banyak menghiasi dunia pendidikan di Indonesia. Hal tersebut dapat kita lihat dengan hadirnya beberapa situs pendidikan baik dari pendidikan regular maupun dari lembaga pendidikan non reguler.

\section{Ruang Lingkup Penelitian}

Dalam penelitian ini permasalahan mencakup :

1. Mengolah data informasi mengenai informasi dan kegiatan sekolah

2. Mengolah data kegiatan dan agenda yang ada dalam sekolah

3. Menghasilkan proses informasi sekolah yang bisa diakses melalui website. 


\section{Gambaran Umum Sistem yang Berjalan}

Flowchart Berfungsi untuk menggambarkan aliran suatu dokumen yang masuk dan keluar dari suatu sistem Berikut ini adalah flowchart sistem informasi sekolah.

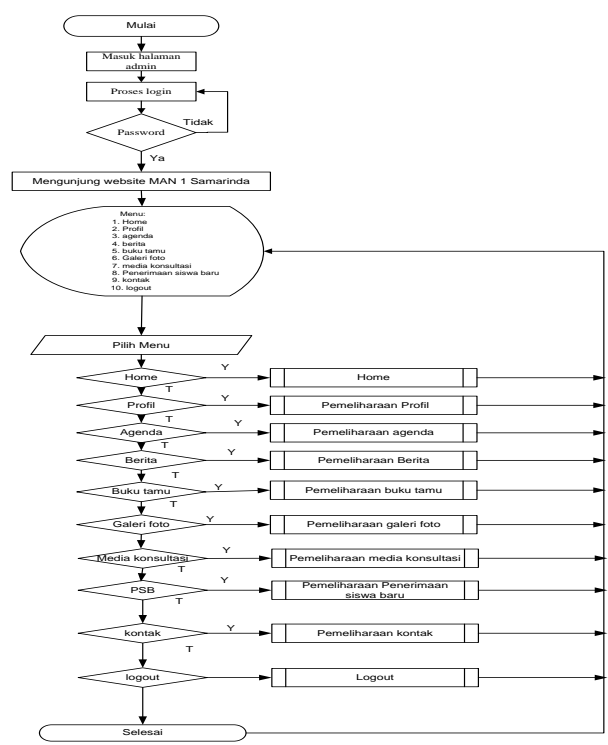

Gambar 1. Flowchart

\section{Sistem}

Menurut Soeherman dkk (2008), kata Sistem mengandung arti sebagai rangkaian komponenkomponen yang saling berinteraksi dan bekerjasama untuk mencapai suatu tujuan.

Jadi dapat diambil kesimpulan dari berbagai teori diatas maka yang dimaksud dengan Sistem adalah seperangkat komponen yang melibatkan manusia, mesin dan metode yang terpadu dan saling berinteraksi untuk mencapai suatu tujuan.

\section{Informasi}

Informasi merupakan hasil pemrosesan data (fakta) menjadi sesuatu yang bermakna dan bernilai untuk pengambilan keputusan. Dalam kehidupan sehari-hari, segala aktivitas pengambilan keputusan kita juga menjadi mudah dengan adanya informasi. Informasi tidak dapat terlepas dari aspek kehidupan manusia. Siapa, kapan, dan dimanapun seseorang akan membutuhkan informasi. (Soeherman dkk, 2008).

\section{Sistem Informasi}

Sistem informasi dapat didefinisikan sebagai suatu sistem dalam suatu organisasi yang merupakan kombinasi dari orang-orang, fasilitas, teknologi, media, prosedur-prosedur, dan pengendalian yang ditujukan untuk mendapatkan jalur komunikasi penting, memproses tipe transaksi rutin tertentu, memberi sinyal kepada manajemen dan yang lainnya terhadap kejadiankejadian internal dan eksternal yang penting dan menyediakan suatu dasar informasi untuk pengambilan keputusan yang cerdik. (Soeherman dkk, 2008).

\section{Internet}

Internet adalah suatu media informasi komputer global yang dapat dikatakan sebagai teknologi tercanggih pada abad ini. Secara etimologis, internet berasal dari bahasa Inggris yakni inter yang berarti antar dan net yang berarti jaringan, sehingga dapat kita artikan sebagai hubungan antar jaringan. Internet merupakan suatu media informasi yang berjalan dalam suatu komputer. Akan tetapi, tidak semua komputer ada yang bisa berhubungan karena suatu komputer dapat dikatakan sebagai internet jika sudah terhubung dengan suatu jaringan (Nugroho, 2004).

\section{Domain}

Setiap tempat komputer yang dihubungkan ke internet memiliki alamatnya sendiri yang unik. Alamat ini terdiri dari dua nama atau lebih, dipisahkan oleh tanda titik dan sekaligus menunjukkan negara, bersifat organisasi, nama organisasi itu sendiri dan mungkin jaringan atau komputer tertentu yang semua itu disebut sebagai Domain (Nugroho, 2004).

Nama domain berfungsi untuk mempermudah pengguna di internet pada saat melakukan akses ke server, selain juga dipakai untuk mengingat nama server yang dikunjungi tanpa harus mengenal deretan angka yang rumit yang dikenal sebagai IP address. Nama domain ini juga dikenal sebagai sebuah kesatuan dari sebuah situs web. Nama domain kadang-kadang disebut pula dengan istilah URL, atau alamat website.

\section{Hosting}

Hosting adalah jasa layanan internet yang menyediakan sumber daya server-server untuk disewakan sehingga memungkinkan organisasi atau individu menempatkan informasi di internet berupa HTTP, FTP, EMAIL atau DNS. Server hosting terdiri dari gabungan server-server atau sebuah server yang terhubung dengan jaringan internet berkecepatan tinggi. (Nugroho, 2004).

Web hosting ada dua macam, yaitu yang membayar seperti: .com, .net, .org. Sedangkan yang gratis seperti: geosities, tripod, f2s dan bravenet.

\section{Browser}

Browser adalah software yang digunakan untuk mengakses atau menampilkan halaman website. Browser berkomunikasi dengan web server melalui protokol HTTP, yang membaca dan menterjemahkan bahasa HTML dan data lainnya dan kemudian menampilkan secara visual sehingga informasi dapat dibaca ( Suyanto, 2007). 


\section{Web Server}

Menurut Mulyanta (2004), Web Server adalah software program yang melayani permintaan client akan halaman web. Software web server ini dijalankan pada setiap komputer sebagai simulasi secara fisik dari sebuah web server betulan secara hardware. Jadi web server disini adalah hanya berupa software aplikasi belaka bukan server betulan secara fisik.

Web Server berupa mesin atau engine yang dapat mengeksekusi browser HTML ke PHP atau ASP beserta database MySQL, Oracle dan sebagainya dalam bentuk $H T M L$, dan web server merupakan inti dari sebuah web hosting.

\section{HTML}

HTML (Hypertext Markup Language) terdiri dari tag-tag yang fungsinya untuk membuat dokumen menjadi dapat dibaca oleh browser. Kata 'Markup Language' pada HTML menunjukkan suatu fasilitas yang berupa tanda tertentu dalam skrip HTML dimana kita bisa mengatur judul, garis, gambar, dan lain-lain dengan perintah khusus. (Prihatna, 2005)

\section{Java Script}

avaScript adalah bahasa pemrograman yang khusus untuk halaman web agar halaman web menjadi hidup. Jika dilihat dari suku katanya terdiri dari dua suku kata yaitu Java dan Script. Java adalah Bahasa pemrograman berorintasi objek, sedangkan Script adalah serangkaian instruksi program. (Nugroho,2004)

\section{Cascading Style Sheet}

Menurut Nugroho (2004) Cascading Style Sheet secara sederhana adalah sebuah metode yang digunakan untuk mempersingkat penulisan tag HTML, seperti font, color, text dan table menjadi lebih ringkas sehingga tidak terjadi pengulangan tulisan.

\section{PHP}

PHP (PHP Hypertext Preprocessor) dikenal sebagai bahasa scripting yang menyatu dengan tag-tag HTML, dieksekusi di server dan digunakan untuk membuat halaman $w e b$ yang dinamis

Menurut Nugroho (2004), PHP merupakan bahasa standar yang digunakan dalam dunia web site. PHP adalah bahasa program yang berbentuk script yang diletakkan di dalam server web. Mulanya PHP diciptakan dari ide Rasmus Lerdorf pada tahun 1995 yang membuat sebuah script Perl. Script tersebut sebenarnya dimaksudkan untuk digunakan sebagai program untuk dirinya sendiri. Tapi, kemudian dikembangkan lagi sehingga menjadi sebuah bahasa yang disebut "Personal Home Page"(PHP). PHP terus berkembang hingga sekarang namanya pun mengalami perubahan menjadi PHP Hypertext Preprocessor (PHP).

\section{XАMPP}

XAMPP merupakan tool yang menyediakan paket perangkat lunak kedalam satu buah paket. Dengan menginstall XAMPP maka tidak perlu lagi melakukan instalasi dan konfigurasi web server Apache, PHP dan $M y S Q L$ secara manual. XAMPP akan menginstalasi dan mengkonfigurasikannya secara otomatis untuk anda atau auto konfigurasi. (Nugroho,2004)

\section{MySQL}

Menurut Nugroho (2004), MySQL (My Structure Query Language) atau yang biasa dibaca "mai-sekuel"adalah sebuah program pembuat database yang bersifat oper source, artinya siapa saja boleh menggunakannya dan tidak dicekal.

Mysql adalah salah satu jenis database server yang sangat terkenal. Kepopulerannya disebabkan MySQL menggunakan SQL sebabai bahasa dasar untuk mengakses databasenya. Selain itu, ia bersifat free (Anda tidak perlu membayar untuk menggunakannya) pada berbagai platform (kecuali pada Windos, yang bersifat shareware atau anda perlu membayar setelah melakukan evaluasi dan memutuskan untuk digunakan untuk keperluan produksi). Perangkat lunak MySQL sendiri bisa di-download dari http://www.mysql.org atau http://www.mysql.com.

\section{Macromedia Dreamweaver}

Dreamweaver adalah salah satu editor web yang banyak digunakan oleh para programmer. Software ini semula dibangun oleh Macromedia, tetapi belakangan diakusisi oleh Adobe (Madcom,2008).

Beberapa kelebihan Dreamweaver antara lain :

1. Pada pemrograman HTML dan XHTML, tampilan situs dapat dilihat tanpa mengunakan browser sehingga memudahkan programmer untuk editing.

2. Dreamweaver medukung pemprograman PHP, ASP, ColdFusion, JSP, CSS, Javascript, dan XML.

3. Dreamweaver dapat membantu webmaster untuk lebih memahami kode-kode pemprograman.

4. Dreamweaver dapat memeriksa jika terjadi kesalahan dalam penulisan sintaks.

5. Membantu dalam mengelola situs yang sedang dibuat.

Mengunakan Dreamweaver tidak sesulit menulis kode program. Tampilan Dreamweaver sangat user friendly, sehingga memudahkan untuk mempelajarinya meski bagi pemula.

\section{PhpMyAdmin}

Ada beberapa cara yang dapat digunakan untuk mengelola database MySQL. Diantaranya melalui prompt DOS (tool command line) dan dapat pula menggunakan program utility seperti PHPMyAdmin, MySQLGUI, MySQL Administrator for Windows. Dalam hal ini penulis akan menggunakan fasilitas PHPMyAdmin untuk mengelola database MySQL. (Bunafit, 2007) 
PHPMyAdmin merupakan salah satu tool manajemen berbasis web, artinya interaksi pemeliharaan dilakukan oleh client dengan menggunakan antarmuka browser.

\section{BAHAN DAN METODE}

\subsection{PENJELASAN BAHAN}

1. Website adalah sebuah situs web adalah sebutan bagi sekelompok halaman web (Web pege). Yang umumnya merupakan bagian dari suatu nama domain atau subdoamain di Worl Wide Web (WWW) di internet. WWW terdiri dari seluruh situs web yang tersedia kepada seluruh situs web yang tersedia kepada publik. Tidak semua situs web dapat diakses dengan gratis. Beberapa situs web memerlukan pembayaran agar dapat menjadi pelanggan, misalanya situssitus berita , layanan surat elektronik (e-mail) dll

2. Internet adalah merupakan jaringan global yang terdiri dari berbagia komputer yang saling berhubungan dengan bekerjasama dengan caraberbagai informasi dan media penghubung tersebut melalui kabel, kanal Satelit maupun frekuensi radio. Setiap komputer yang terhubung dengan jaringan tersebut diberikan sebuah nomor yang unik, dan berkomunikasi yang sama. Bahasa komunikasi yang ini sisebut protokol. Protokol yang digunakan TCP/IP (Transmission control protocol internet protocol)

\subsection{METODE AIR TERJUN}

Model air terjun (waterfall) adalah membantu mengatasi kerumitan kerumitan yang terjadi akibat proyek proyek pengembangan perangkat lunak. Seperti pada gambar 2 sebuah model air terjubn memacu pada tim pengembang untuk merinci apa yang seharusnya pernkat lunak lakukan (menentukan dan mengumpulkan kebutuhan sistem) sebelum sistem tersebut dikembangkan .

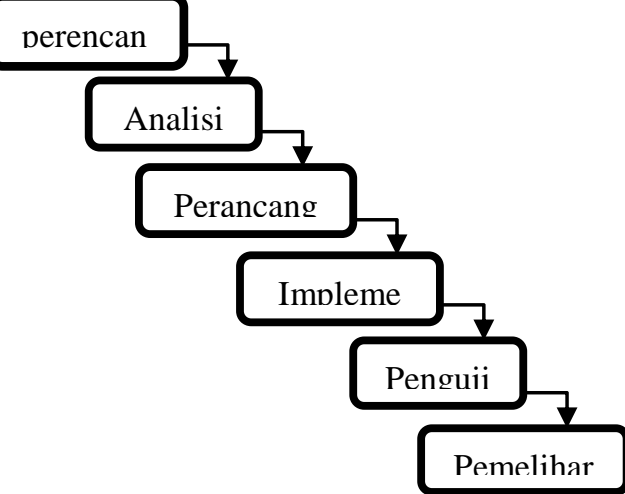

Gambar 2 : Metode Air Terjun
4. RANCANGAN SISTEM DAN APLIKASI

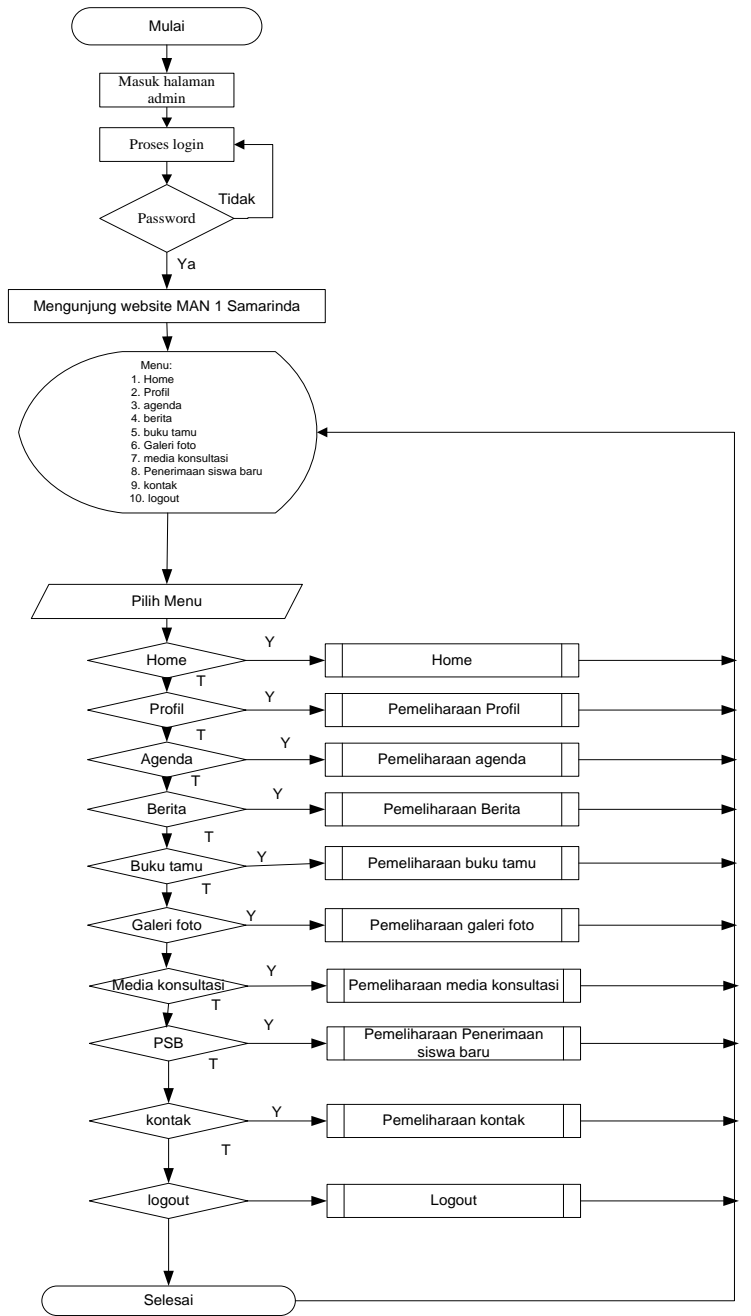

Gambar 3 . flowchart Admin 


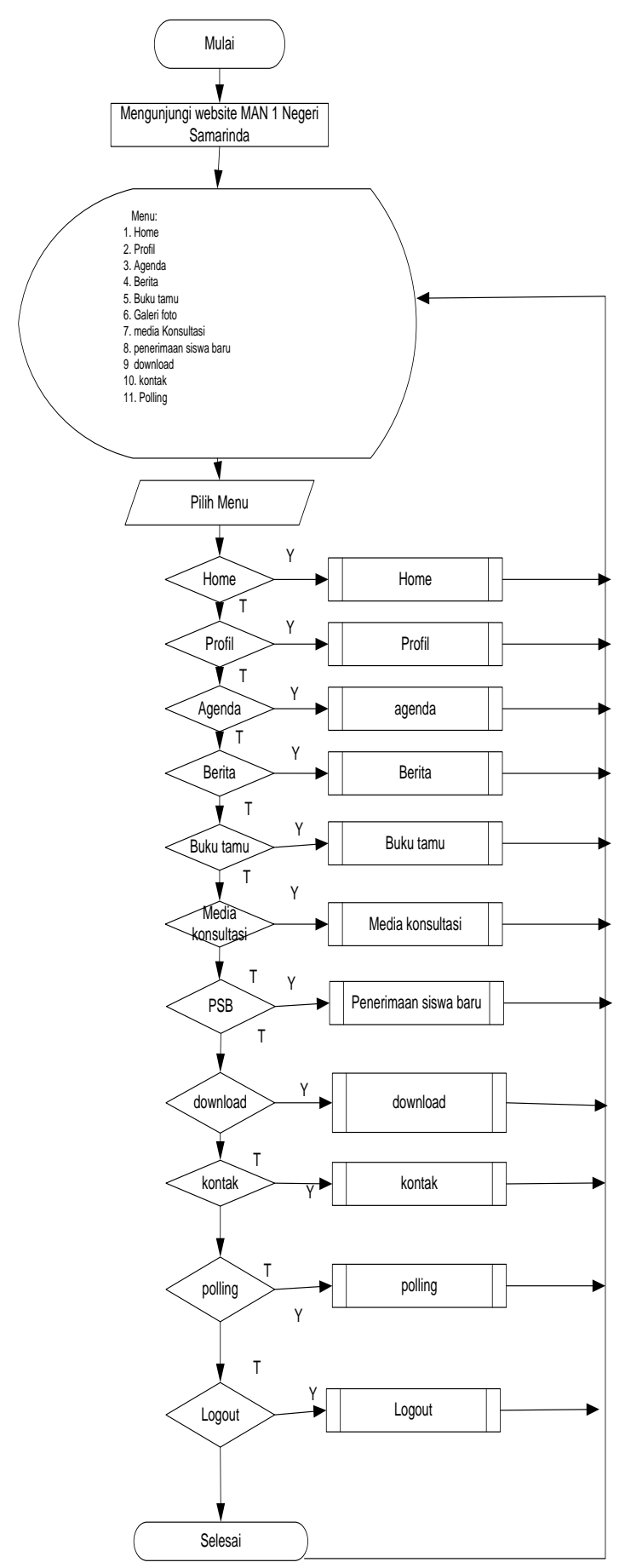

Gambar 4. Flowchart admin

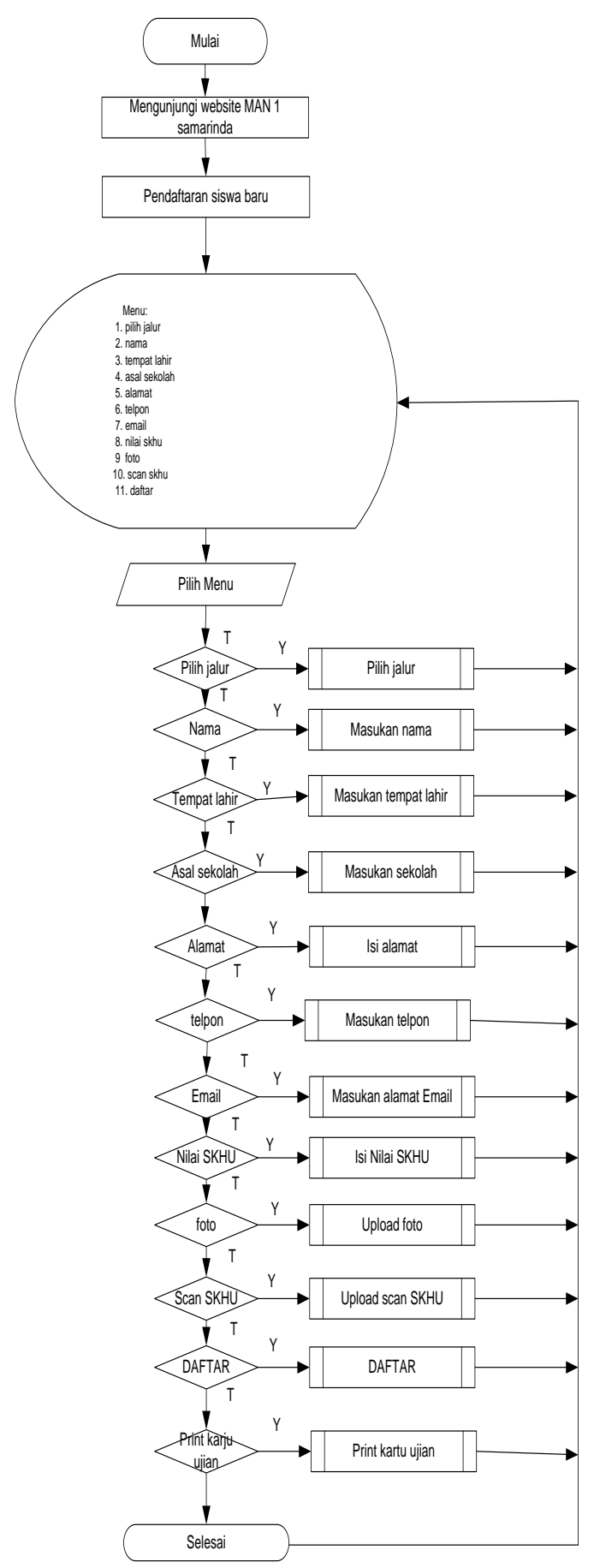

Gambar 5. Flowchart pendaftaran siswa baru 


\section{IMPELEMNTASI}

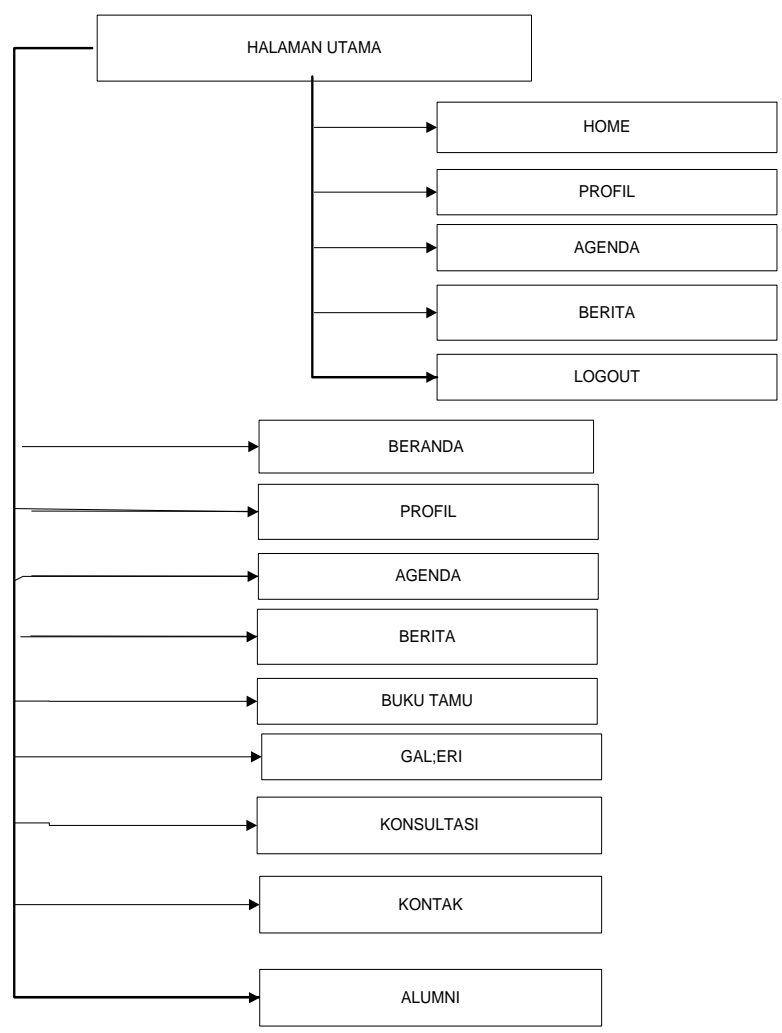

Gambar 6. Gambar Sitemap sistem informasi sekolah madrasah aliyah negeri 1 samarinda.

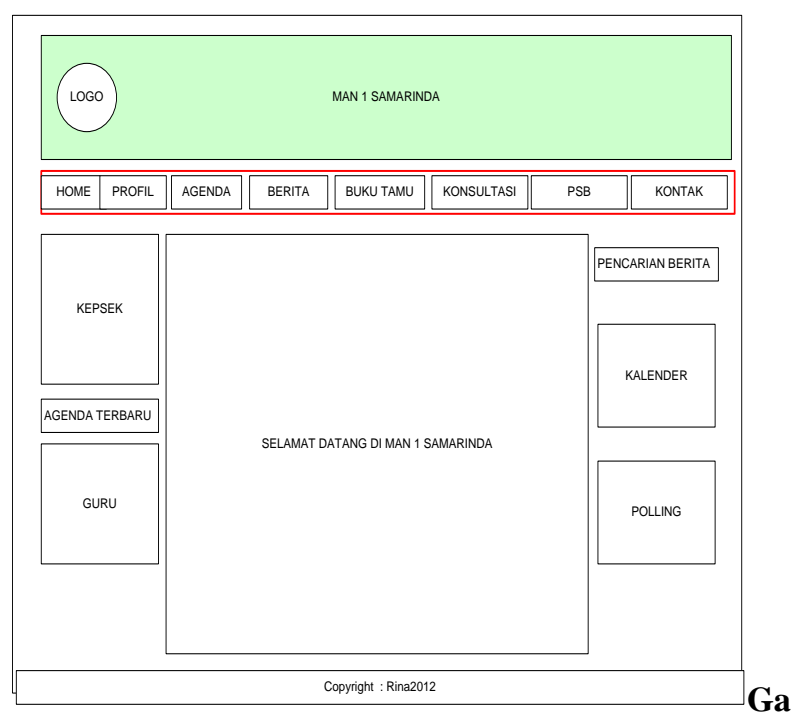

mbar 7. Desain Layout

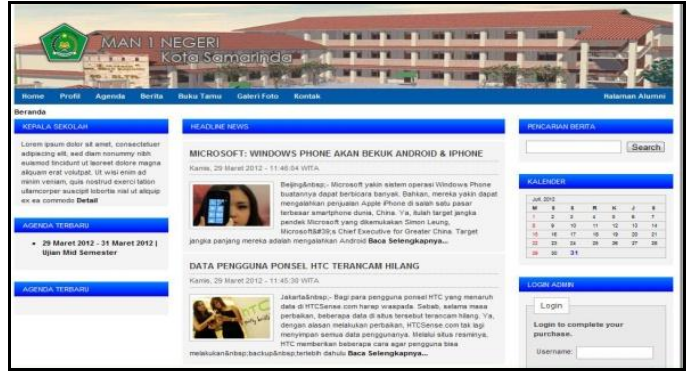

Gambar 8. Halaman beranda

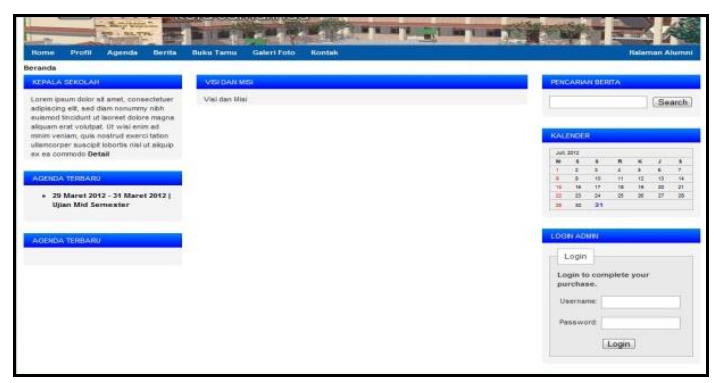

Gambar 9. Profil

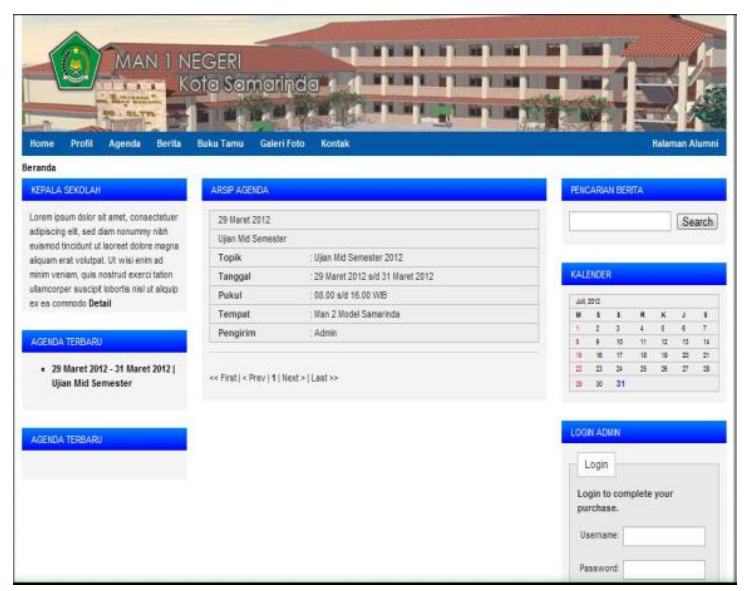

Gambar 10. Agenda

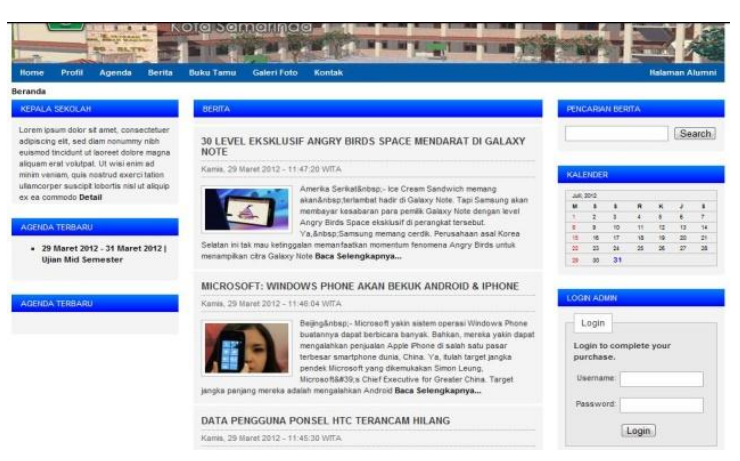

Gambar 11. Berita 


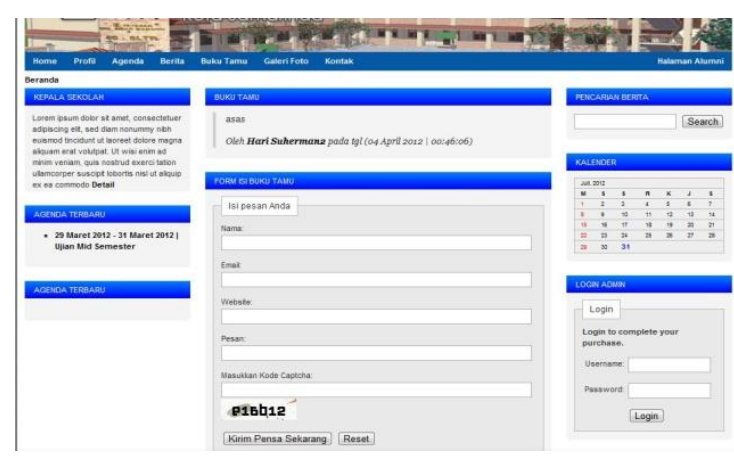

Gambar 12. Buku Tamu

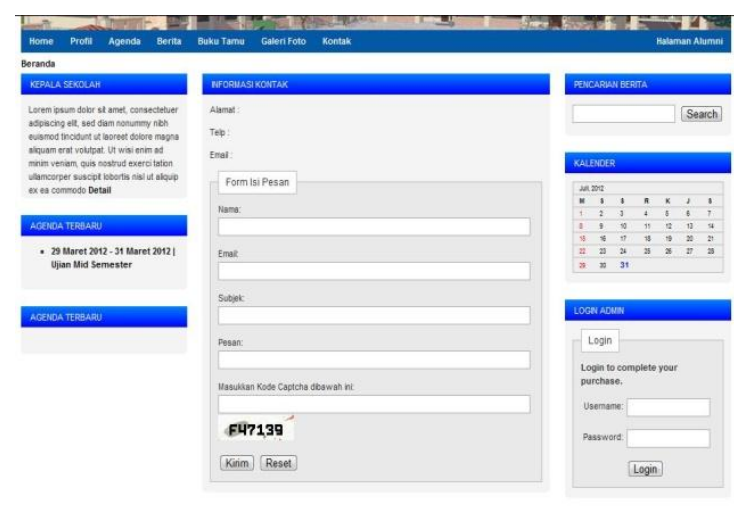

Gambar 13. Kontak

6. KESIMPULAN

1. Dengan adanya "Sistem Informasi Sekolah Madrasah Aliyah Negeri 1 Samarinda Berbasis Web", maka mempermudah dalam proses penyampaian informasi kepada masyarakat umum

2. Dengan adanya website ini konsultasi dan ikatan alumni Sekolah Madrasah Aliyah Negeri 1 Samarinda dapat dilakukan melalui website ini.

3. Dengan adanya website dapat mempromosikan Madrasah Aliyah Negeri 1 Samarinda

4. Dengan adanya website ini dapat menginputkan kritik dan saran yang nantinya akan digunakan sebagai koreksi bagi pihak Sekolah Madrasah Aliyah Negeri 1 Samarinda agar lebih baik lagi.

\section{Saran-Saran}

Berdasarkan kesimpulan diatas, maka penulis memberikan saran-saran yaitu, bagi mahasiswa yang berminat untuk mengmbangkan Sistem Informasi Sekolah Madrasah Aliyah Negeri 1 Samarinda, dapat menambahkan fasilitas yang nantinya dapat membuat website Sekolah Madrasah Aliyah Negeri 1 Samarinda lebih interaktif.

\section{DAFTAR PUSTAKA}

Hengky Prihatna, 2005, Kiat Praktik Menjadi Webmaster Profesional

Jogiyanto HM., 2003, Analisis \& Desain Sistem Informasi Manajement, Andi Yogyakarta,

Madcoms, 2008, Aplikasi program PHP dan MYSQL Untuk Membuat Website Interaktif, Andi, Yogyakarta.

Musyawarah, 2004, Macromedia Studio MX ( Integrasi Aplikasi Untuk Membangun Website ), Andi Yogyakarta.

Mulyanta, edy s. 2002. macromedia studio MX (integrasi aplikasi untuk membangun website). Andi. Yogyakarta.

Nugroho, Adi. 2010, Rekayasa Perangkat Lunak Dengan Metode USDP, Yogyakarta: Penerbit Andi

Nugroho, 2004, PHP \& My SQL dengan editor Dreamewaver MX, Andi, Yogyakarta.

Nugroho, bunafit 2007, Membuat Website Sendiri Dengan PHP dan MYSQL , Andi, Yogyakarta

Pressman, Roger S, 2003, Rekayasa Perangkat Lunak: pendekatan praktisi (Buku I). Andi, Yogyakarta. 